\title{
Stature, Age, and Gender Effects on Reach Motion Postures
}

\author{
Don B. Chaffin and Julian J. Faraway, University of Michigan, Ann Arbor, Michigan,
} Xudong Zhang, University of Illinois, Urbana-Champaign, Illinois, and Charles Woolley, University of Michigan, Ann Arbor, Michigan

\begin{abstract}
The rapid adoption of software to simulate human reach motions in the design of vehicle interiors and manufacturing and office workstations has required a sophisticated understanding of human motions. This paper describes how more than 3000 right-arm reaching motions of a diverse group of participants were captured and statistically modeled. The results demonstrate that stature and age have a larger effect than does gender on reach motion postures for motions chosen by the participants while reaching to targets placed throughout a typical automobile interior. We propose that these methods, models, and results can assist the further development of human motion simulation software for ergonomic purposes, such as for the design or evaluation of vehicie interiors or industrial workplaces, to ensure that various population groups are physically accommodated.
\end{abstract}

\section{INTRODUCTION}

Many common tasks require that a person coordinate the movement of multiple segments of the body to reach successfully to a designated location in space. The task of interest in this paper is reaching to a variety of locations within the interior of an automobile (e.g., moving the right hand from the steering wheel to the center console, overhead console, radio, or passenger side door). Some of these motions can require one not only to extend the upper extremity toward the designated target location but also to rotate the shoulder and torso to assist in the motion. As described in a recent study by Zhang and Chaffin (1997), these types of motions can be modeled based on a four-segment linkage system consisting of torso, shoulder, arm, and forearm-hand segments. Various empirical and kinematic modeling approaches have been used to predict these types of complex motions (see Badler, Phillips, \& Webber, 1993, for further information on these models).

The purpose of this paper is to empirically describe and analyze the effects of size, age, and gender on the postures chosen while performing these types of reaching motions. If these three demographic effects can be satisfactorily quantified, the understanding of human motion will be enhanced and future human motion simulation software will more accurately reflect these population attributes in the resulting motion predictions.

There is little debate that the size of an individual often has an important effect on postures when the reach target is located away from the body. In a static sense, when the upper extremity is extended so that the handforearm-arm segments are nearly aligned, the reach boundary is defined by the length of these body segments unless the shoulder and torso are also allowed to move toward the target. Computerized human reach simulations, such as those performed by SAMMIET, Crewchief $^{\text {TM, SAFEWORK }}{ }^{\mathrm{TM}}$, and JACK ${ }^{\mathrm{TM}}$, often predict reach boundary conditions without shoulder and torso assistance, unless the user specifically modifies the initial torso and shoulder postures (Karwowski, Genaidy, \& 
Asfour, 1990). This strategy, though rendering useful approximations of extreme reach postures, does nothing to assist a workplace or vehicle designer in understanding how differentsize people actually choose to move and position themselves when performing a variety of reach tasks in their particular reach boundary conditions. This latter type of information is valuable in designing a workspace in which a person can reach to various areas in an unobstructed fashion.

A reason to believe that age could affect complex reaching motions is derived from the following studies. The most general evidence is from the 1987 National Health Interview Survey (Supplement on Aging), in which selfreports of performance declines by older individuals were greater in motor tasks requiring multisegmental coordination (e.g., reaching overhead, crouching, lifting objects, and bathing) than in simpler motions (e.g., shaking hands or eating; Lawton, 1990). Also, one laboratory study of 61 participants 20 to 80 years of age by Potvin, Syndulko, Toutellotte, Lemmon, and Potvin (1980) disclosed that decreases in performance time were greater with age when the tasks required multisegmental motions (e.g., cutting with a knife or putting on a shirt), than with simpler motions. Ball-throwing motion studies by Haywood, Williams, and VanSant (1991) revealed that older adults tended not to rotate their trunk and arm as much as younger adults did. They conjectured that these changes could be caused by loss of flexibility in the shoulder girdle; by fear of pain (or actual pain), inhibiting torso and shoulder motions that approach one's range of motion at a joint; or by the desire to protect against postexertion soreness. Finally a recent study by Cavanaugh et al. (1999) disclosed that in standing forward reaches, older participants tended not to rotate and flex their torsos as much as younger ones did, thus demonstrating diminished maximum volitional reach capability with age.

Even though most normal reaching motions in daily activities do not require maximum effort, muscle strength does become important as the motion of a particular segment approaches the end of a joint's volitional range of motion. Because muscle strengths vary by as much as
15:1 in the normal healthy population (Chaffin, Andersson, \& Martin, 1999), and because women's shoulder and arm strengths average about $55 \%$ of men's (Laubach, 1978), extended reaches in which the shoulder is highly stressed may result in a woman's motions being different from a man's. A comparison study (Chaffin, Georgi, Baker, \& Nussbaum, 1998) of six women and six men performing reaches to a passenger side door indeed disclosed that the shoulder strength requirements, when the upper extremity was extended toward the passenger door, were equivalent to $34 \%$ of the average woman's strength and $26 \%$ of the average man's strength. Others (Gallagher, Zuckerman, Cuomo, \& Ortiz, 1996; Kumar, Chaffin, \& Redfern, 1988; Murray, Gore, Gardner, \& Mollinger, 1985; and Yates, Kamon, Rodgers, \& Champney, 1980) have shown that age (particularly after about age 50) is associated with a general decrease in population strengths. Collectively, these studies support the hypothesis that older women demonstrate less arm abduction/llexion angles than do younger men when reaching away from the body and, thus, may use more torso compensation (motions) to complete such a reach.

To test these hypotheses, we asked a group of men and women of varied statures and ages to sit in a driving simulator and reach to various targets while being carefully monitored with a three-dimensional (3D) motion capture system. The resuling motion data were used to derive joint angle changes for each reach, which were then analyzed by a new functional regression analysis method to determine the potential effects of stature, gender, and age.

\section{METHODS}

\section{Participants}

Thirty-eight participants 20 men and 18 women), demographically representative in terms of stature and age of drivers, volunteered to serve in the experiment and were paid for their participation. Table 1 presents the mean and standard deviation values of age and gross anthropometry of these 38 participants. These values compare reasonably well 
TABLE 1: Mean and Standard Deviation Values of Participants' Age, Stature, and Weight

\begin{tabular}{llll}
\hline Gender & Age (years) & Stature $(\mathrm{cm})$ & Weight $(\mathrm{kg})$ \\
\hline Female $(n=18)$ & $34.2 \pm 14.1$ & $162.2 \pm 8.8$ & $60.9 \pm 10.7$ \\
Male $(n=20)$ & $36.3 \pm 16.8$ & $175.2 \pm 9.4$ & $79.3 \pm 15.6$ \\
Overall $\langle N=38)$ & $35.3 \pm 15.4$ & $171.3 \pm 11.1$ & $70.6 \pm 16.2$ \\
\hline
\end{tabular}

with those published for the U.S. population in general (NCHS, 1976).

\section{Experimental Procedures}

The experiment was conducted in a driving simulator developed in the Center for Ergonomics at the University of Michigan. The driving simulator consisted of a mock-up of a vehicle with a driving scene graphically rendered on a big-screen monitor in front of the vehicle, coupled to the primary controis (e.g., steering wheel, accelcrator and brake pedals) of the vehicle. As illustrated in Figure 1, 38 targets, grouped into five areas emulating typical zones to which a driver would normally reach, were presented in the simulated vehicle. These five target areas included a center console, instrument panel (radio and climate control), overhead console, glove box, and passenger- side door. The later statistical analysis combines reaches to the glove box and passenger door and refers to these as far reaches toward the passenger-door area.

During the driving task, participants were intermittently signaled, by a graphic on the video monitor and a tone, to reach toward one of the 38 targets in a natural manner and to touch a small switch at the target. When the extended finger touched the target switch, they would remain in that posture for about $3 \mathrm{~s}$, and then a tone would signal them to return to the original driving posture. Each reach was repeated once, and the order of a total of 76 reaching movements was randomized. A practice session was provided to allow participants to gain suffcient familiarity with the tasks. The fore and aft seat position was adjusted as preferred by each participant at the beginning of the experiment,

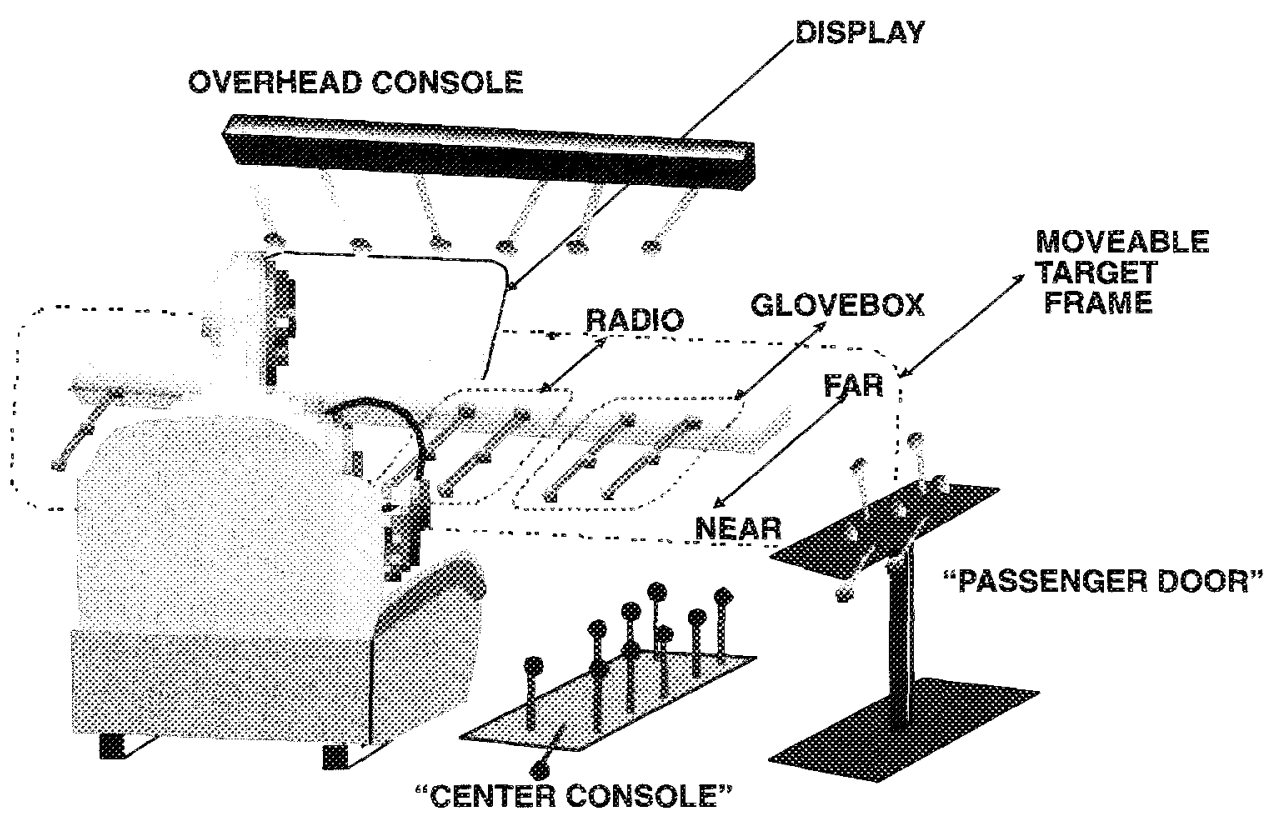

Figure 1. Rear view of driving simulator and reach targets (not to scale). 
but up-down and tilting motions were fixed. The seat pan had a $9^{\circ}$ angle from horizontal, and the back rest had a $22^{\circ}$ angle from vertical. The seat had medium-sized side bolsters on the seat pan and seat back.

Spherical reflective markers were placed on paipable body landmarks identifying the right wrist, right elbow, right shoulder, suprasternale, and right and left anterior-superior iliac spine (ASIS), as well as on a head-mounted frame (see Figure 2). An optoelectronic motion analysis system (MacReflex ${ }^{\mathrm{TM}}$, Qualisys Inc., Glaston, CT) with four cameras captured the motions of these markers at a sampling frequency of $25 \mathrm{~Hz}$. This system has the ability to track the captured motions as a succession of two-dimensional images (four images corresponding to four cameras for each time frame), and then delivering the 3D Cartesian coordinates of the markers as a time series.

A four-segment biomechanical linkage that represents the torso and upper extremity (Figure 2) was constructed by connecting the wrist joint, elbow joint, shoulder (glenohumera) joint, suprasternale, and the bottom of the torso. A separate neck-head link was included, but the analysis of motions of this segment is not included here. In addition, for graphic purposes, the torso link included a pelvic triangular linkage, which was scaled and positioned in the sagittal plane as described in Chaffin, Faraway, and Zhang (1999).

The 3D coordinates of the surface markers for the wrist, elbow, and shoulder were translated into the corresponding internal joint centers using a procedure developed by Nussbaum, Zhang, Chaffin, Stump, and Raschke (1996). Implicit in this linkage representation are three assumptions: (a) the four body seg. ments contained in the system are rigid links; (b) the right hand is considered as a rigid extension of the forearm (i.e., there is no relative motion between the hand and forearm and the distal tip of the extended index finger is the end of this link); and (c) the bottom of the torso link is estimated as an axis connecting the two ASIS markers. Based on this linkage, the 18 joint angles defined in Table 2 were computed for every time frame. The profiles of these joint angles described the

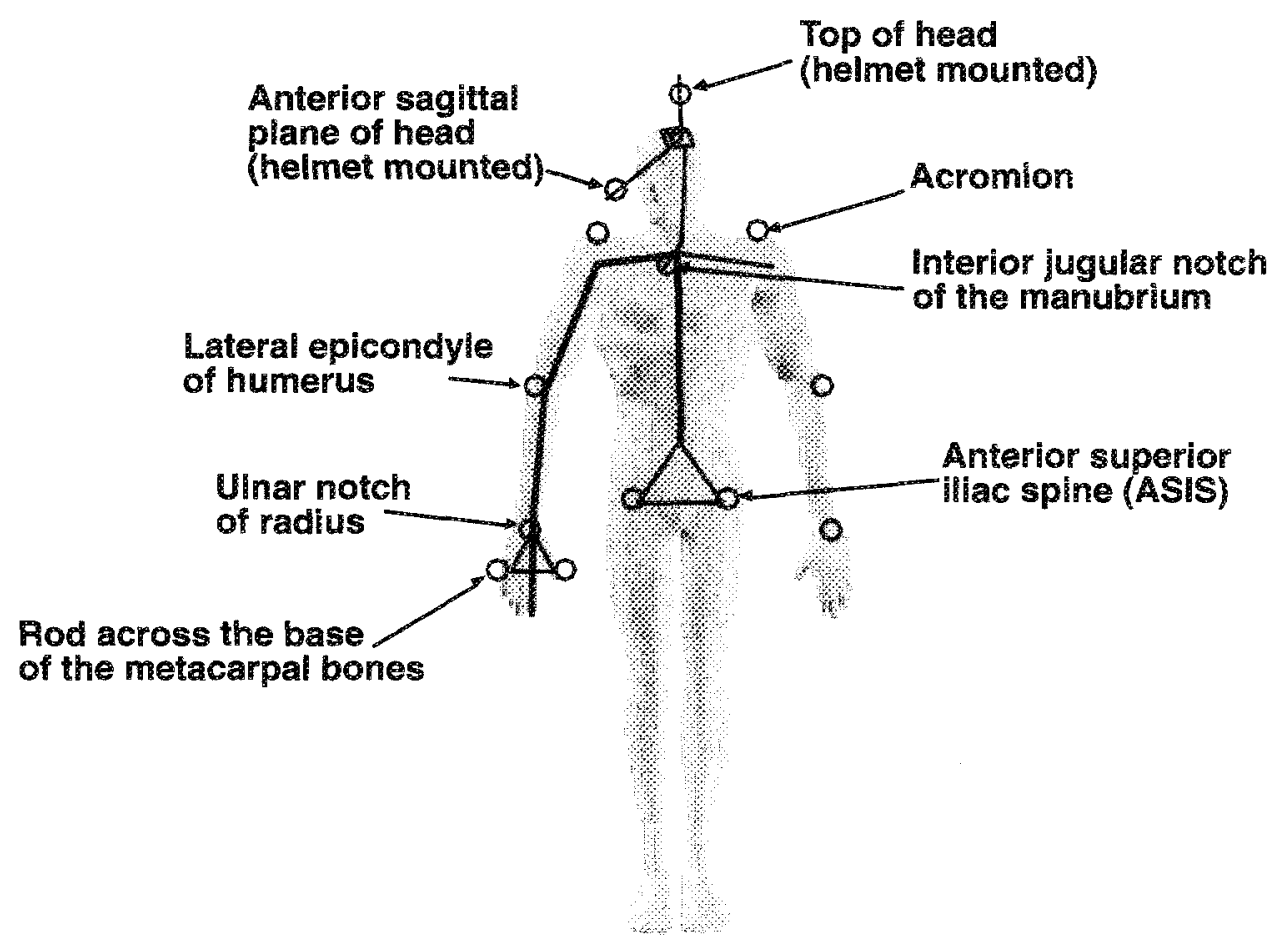

Figure 2. Depiction of linkage system and body surface markers. 
TABLE 2: Angles Used to Define Postures and Motions

\begin{tabular}{ll}
\hline \multicolumn{1}{c}{ Global Angles } & Local lncluded Angles \\
\hline 1. Trunk forward flexion & 1. Neck-head flexion \\
2. Trunk lateral flexion & 2. Neck-head rotation \\
3. Trunk axial rotation & 3. Neck-head lateral \\
4. Arm vertical & 4. Shoulder vertical (relative to torso) \\
5. Arm horizontal & 5. Shoulder horizontal (relative to torso) \\
6. Forearm vertical & 6. Humeral rotation \\
7. Forearm horizontal & 7. Elbow included \\
8. Hand vertical & 8. Forearm rotation (supination/pronation) \\
9. Hand horizontal & \\
10. Hand rotation & \\
\hline
\end{tabular}

time-varying joint kinematics during each measured reaching movement. These joint angle data then served as the input for the subsequent statistical analysis to allow us to determine the significant effects of stature, age, and gender.

\section{Statistical Analysis}

A more detailed description of the statistical methods used in this paper may be found in Faraway (1997), and a general exposition of the analysis of functional data appearing in Ramsay and Silverman (1997).

As an example of the data, the elbowincluded angle when reaching to the glove box area is depicted in Figure 3. As shown, the angular changes for each reach are relatively smooth. Because the motion times when reaching to the 38 targets varied among people and target locations, the data were rescaled so that the motion times represent the proportion of

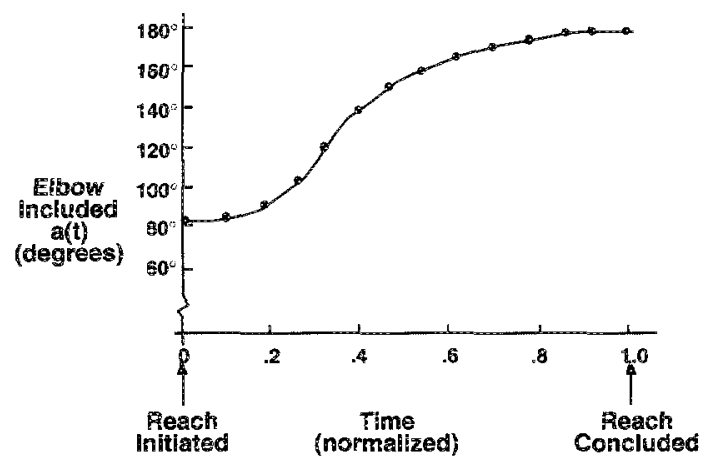

Iigure 3. Typical elbow-included angle data with a smoothing spline function. time required to complete a motion. This allowed the angle values for each joint to be directly compared for each of the experimental conditions of interest throughout the movement without the confounding effects of slow and fast motions. This normalizing procedure was also justified by an earlier study (Zhang \& Chaffin, 1997), which concluded that instantaneous postures were not significantly affected by the speed of reaching movements when performed no faster than about $20 \%$ above their chosen normal speed.

Though both global and local joint angles were computed for the reach motions, only the following six angles are reported here: trunk forward flexion (global), trunk lateral flexion (global), trunk rotation (global), shoulder vertical deviation of arm from torso (local), shoulder horizontal deviation of arm from torso (local), and elbow flexion included angle (local). We believe that these six angles are the most intuitive angles and, generally, are independent of one another (e.g., if one laterally flexes the torso with the arm held in a constant posture relative to the torso, the included shoulder vertical abduction angle values will not change, given that they are defined with a local coordinate system that rotates with the torso).

The statistical model used to determine the potential effect of stature, gender, and age on these six angles is

$$
\begin{aligned}
& a_{\mathrm{j} \mathrm{k}}(t)=\beta_{0}(t)=\beta_{\mathrm{x}}(t) x_{\mathrm{j}}+\beta_{\mathrm{y}}(t) y_{\mathrm{j}}+\beta_{\mathrm{z}}(t) z_{\mathrm{j}}+ \\
& \beta_{\mathrm{h}}(t) h e i g h t_{\mathrm{i}}+\beta_{\mathrm{a}}(t) a g e_{\mathrm{i}}+\beta_{\mathrm{s}}(t) \operatorname{sex}_{\mathrm{i}}+\varepsilon_{\mathrm{j} \mathrm{j}}(t),
\end{aligned}
$$

where height $t_{\mathrm{i}}$ is standing height in centimeters 
of individual $i$; age is 0 for those younger than 50 years and 1 for 50 years or older; se $x_{\mathrm{i}}$ is 0 for female and 1 for male; $\left(x_{i}, y_{j}, z_{j}\right)$ are the coordinates of the $j$ th target; and $a_{\mathrm{ijk}}(t)$ is the angle curve over time for individual $i$, target $j$, and replicate $k(k=1,2)$. More precisely, the $\left(x_{\mathrm{j}}, y_{\mathrm{j}}, z_{\mathrm{j}}\right)$ are measured relative to an origin, defined as the right ASIS point for the participant.

Each participant was allowed to adjust the seat position in the fore and aft directions; thus targets requiring forward reaches (e.g., toward the radio) might not be as susceptible to the participants" anthropometry as those to the side (toward the passenger door). Because it is a normal condition of driving that drivers can adjust their seat fore and aft position, allowing this adjustment in this study appeared to be warranted. This would have the potential for reducing the effects of anthropometric variations when reaching to targets near the sagittal plane, but it would not have as much effect on lateral target reaches. The results are presented for each target area separately to better understand this potential difference.

The coefficient curves are $\beta(t)$, which are estimated by fixing $t$ for each proportional time period. In essence, the model becomes the usual multiple linear regression model, the estimated coefficients of which give the values of $\beta(t)$ at each chosen $t$ interval for a designated target location. To derive a comparison curve, we simply repeated the process for an evenly spaced grid of 20 values and for each target and demographic condition. The standard errors and other common regression statistics are computed pointwise for the 20 periods and for each experimental condition. Coefficient of determination $r^{2}$ values disclose that about $70 \%$ of the variance in the angle data are accounted for with this type of model (Chaffin, Faraway, \& Zhang, 1999).

Faraway (1997) provided additional details on the construction of the model. One of the advantages of such a model is that residual curves may be calculated and examined. Outliers and influential observations may be detected in a manner analogous to standard regression. Adequacy of fit may also be checked by comparing the residual variation in our models with the variation found in repli- cated reaches. We performed these checks for all the models used here and verified their adequacy.

The inclusion of only one anthropometric variable (i.e., stature) in the statistical model was based on a stepwise procedure in which body weight, arm length, seated height, and several other anthroponetric variables were systematically added to the regression model. None of these had a statistically significant effect beyond that provided by stature alone.

\section{RESULTS}

The statistical results are presented graphically; the $\beta(t)$ effects (solid line) and $95 \%$ pointwise confidence bands (dotted lines) that were found to be most significant are depicted for the six major included body angles. Because the direction of the reach motion affects the particular angles of interest, results are presented by the four reach zones (i.e., reaches to the radio, center console, overhead console, and far right reaches toward the glove box and passenger door).

Only those angles for which stature, gender, or age had both a statistically significant $(t>$ 2.0) effect and a practical effect (greater than an estimated $1^{\circ}$ difference in an angle) are depicted graphically. To illustrate the practical effects of the angle differences on chosen postures, the results are also depicted with a $3 \mathrm{D}$ stick figure in several terminal postures required to reach some of the targets.

\section{Stature Effects on Reaching Postures}

Because the participants were allowed to adjust the fore and aft position of the seat prior to beginning each experimental session, it was possible that stature (which varied from about $144 \mathrm{~cm}$ to $195 \mathrm{~cm}$ ) would have a significant effect on some of the far side and overhead reaches but less effect on the forward reaches to the radio and center console. Indeed, this appears to be the case; Table 3 depicts the significant angle effects (per $10 \mathrm{~cm}$ of stature) at the destination of the reaches to the four target areas.

Inspection of Table 3 indicates that when reaching to the far targets located to the side (i.e., glove box and passenger door handle), 
TABLE 3: Significant Mean Changes in Six Major Body Angles for Each $10 \mathrm{~cm}$ of Stature when the Hand Reached to the Four Target Areas

\begin{tabular}{lllllll}
\hline $\begin{array}{l}\text { Target } \\
\text { Area }\end{array}$ & $\begin{array}{l}\text { Trunk } \\
\text { Forward }\end{array}$ & $\begin{array}{l}\text { Trunk } \\
\text { Lateral }\end{array}$ & $\begin{array}{l}\text { Trunk } \\
\text { Rotation }\end{array}$ & $\begin{array}{l}\text { Shoulder } \\
\text { Vertical }\end{array}$ & $\begin{array}{l}\text { Shoulder } \\
\text { Horizontal }\end{array}$ & $\begin{array}{l}\text { Right } \\
\text { Elbow }\end{array}$ \\
\hline Console & $n s$ & $-0.5^{\circ}$ & $n s$ & $-2.1^{\circ}$ & $3.0^{\circ}$ & $-7.1^{\circ}$ \\
Radio & $3.3^{\circ}$ & $-1.0^{\circ}$ & $2.0^{\circ}$ & $-7.4^{\circ}$ & $n s$ & $-4.1^{\circ}$ \\
Overhead & $1.1^{\circ}$ & $-0.4^{\circ}$ & $1.8^{\circ}$ & $-9.9^{\circ}$ & $n s$ & $-10.3^{\circ}$ \\
Far Right & $6.1^{\circ}$ & $-6.2^{\circ}$ & $2.9^{\circ}$ & $-10.0^{\circ}$ & $3.1^{\circ}$ & $-2.0^{\circ}$ \\
\hline
\end{tabular}

Note: $n s$ = no significant difference could be found.

stature had its greatest effect: Taller people had to use far less trunk lateral bending (about $6^{\circ}$ less $/ 10 \mathrm{~cm}$ of height) and shoulder vertical (abduction) angle (about $10^{\circ}$ less $/ 10 \mathrm{~cm}$ ) than did shorter individuals. Increased stature also had a profound effect on the amount of shoulder vertical abduction and elbow flexion angle (about $10 \% 10 \mathrm{~cm}$ ) when reaching to the overhead console.
The angle effects and 95\% confidence intervals for these four major angle changes throughout the reach motions are depicted in Figure 4. These graphs depict how the angles change for each $10 \mathrm{~cm}$ of additional stature. As can be seen, the greatest effect of increased stature is toward the end of the reach motions.

A stick figure of the postures predicted by the functional regression model for two

Far Right Reaches towards Glove Box and Passenger Door
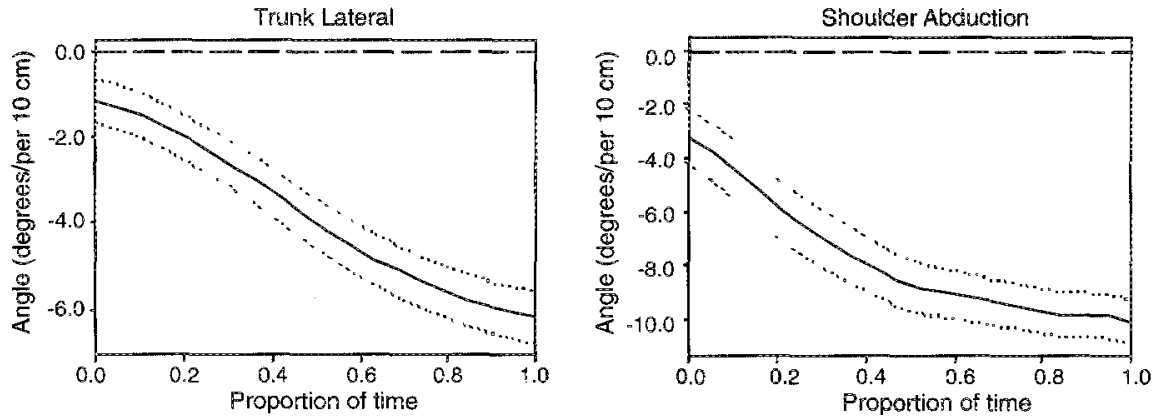

Reaches to Overhead Console
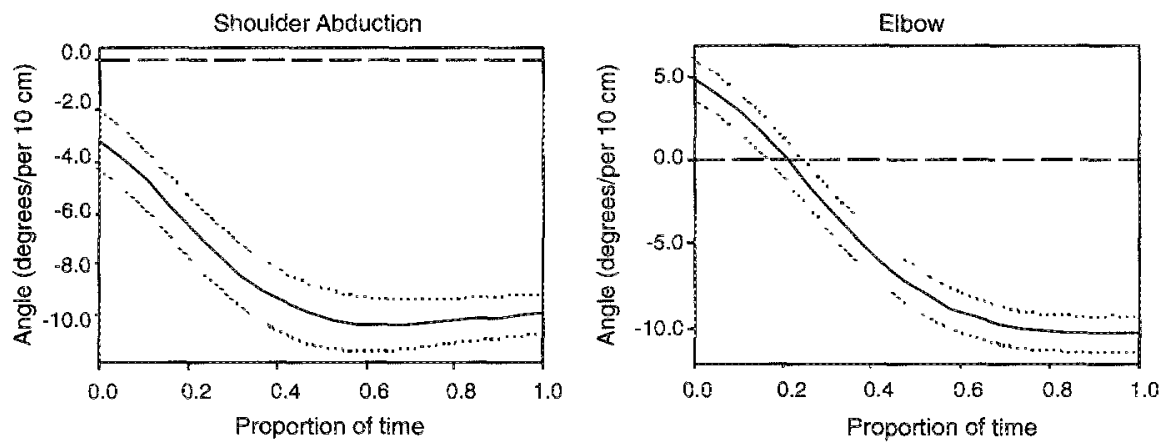

Figure 4. Mean and 95\% confidence lines for four angles atributable to stature (angle differences in degrees per $10 \mathrm{~cm}$ of stature). 
extreme-stature men is depicted in Figure 5. This demonstrates the average effect of stature alone when performing a lateral far right reach, independent of gender and age. The additive effect of gender and age is presented next.

\section{Gender Effects on Reaching Postures}

Because anthropometry (other than stature) and gender may have a covariate effect, care must be taken when analyzing the effect of gender alone on reaching postures. The results assume that stature accounts for all of the anthropometric effects regardless of gender. This may not be the case (e.g., on average the shoulder breadth for women is generally narrower than that for men, regardless of stature). Other gender-related attributes, such as strength, may also affect the differences, as discussed earlier.

Once again, using the postures at the end of the reaches to the four target reach areas for comparison, we found that some men's postures are significantly different from those of women, as depicted in Table 4. In general, however, the gender effects in these data are small (less than $3^{\circ}$ ). Two of the largest joint angle differences during the reach motions are depicted in Figure 6 for shoulder vertical abduction (during the far-right-side glove box and passenger-door reaches) and for elbow flexion (for overhead console reaches). These indicate that men tended to have slightly less shoulder angle abduction and elbow flexion than did women for these reaches, especially toward the latter phase of the reach motions.

\section{Age Effects on Reaching Postures}

To evaluate the potential effect of age, inde-

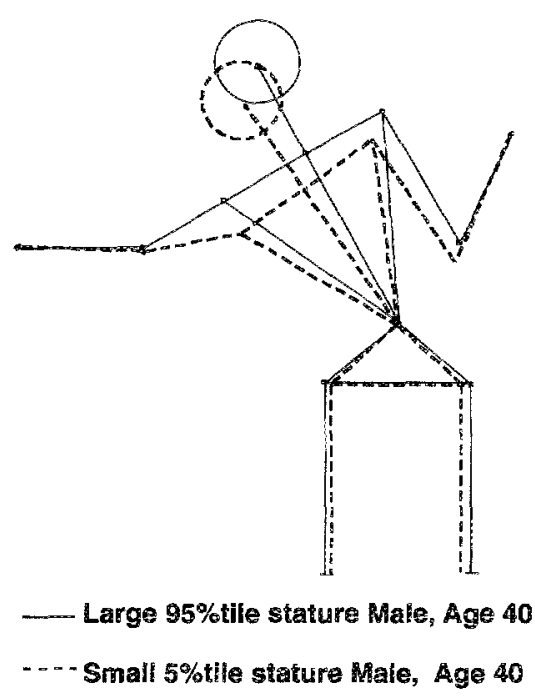

Figure 5. Stick figure representations of two extreme-size men reaching to far-right passenger door location.

pendent of gender and stature, an analysis was performed to determine the potential effects of being younger or older than 50 years. The threshold age of 50 was chosen because many individuals are very active and drive vehicles in their $50 \mathrm{~s}$ and $60 \mathrm{~s}$, and yet concern is often expressed about the possibility of declining perceptivemotor capabilities beginning around this age, as discussed in the introduction. Of the 38 participants, 14 were $50+$ years old (the oldest was 74 years old), which provided enough statistical power to test the effect of age. In the resulting statistical regression model, age is treated as a continuous variable with a linear effect on joint angles because the sample size was not large enough to test nonlinear models.

Table 5 depicts the mean effects for the

TABLE 4: Summary of Significant Mean Changes in Six Major Body Angles (in degrees) for Males Compared with Females when the Hand Reached the Four Final Target Areas

\begin{tabular}{lllllll}
\hline $\begin{array}{l}\text { Target } \\
\text { Area }\end{array}$ & $\begin{array}{l}\text { Trunk } \\
\text { Forward }\end{array}$ & $\begin{array}{l}\text { Trunk } \\
\text { Lateral }\end{array}$ & $\begin{array}{l}\text { Trunk } \\
\text { Rotation }\end{array}$ & $\begin{array}{l}\text { Shoulder } \\
\text { Vertical }\end{array}$ & $\begin{array}{l}\text { Shoulder } \\
\text { Horizontal }\end{array}$ & $\begin{array}{l}\text { Right } \\
\text { Elbow }\end{array}$ \\
\hline Console & ns & $1.0^{\circ}$ & $1.0^{\circ}$ & $2.0^{\circ}$ & $n s$ & $-2.8^{\circ}$ \\
Radio & $n s$ & $n s$ & $1.2^{\circ}$ & $n s$ & $-1.0^{\circ}$ & $-2.2^{\circ}$ \\
Overhead & $n s$ & $1.3^{\circ}$ & $n s$ & $-1.0^{\circ}$ & $n s$ & $-2.4^{\circ}$ \\
Far Right & $1.9^{\circ}$ & $-1.2^{\circ}$ & $n s$ & $-2.5^{\circ}$ & $1.5^{\circ}$ & $-1.5^{\circ}$ \\
\hline
\end{tabular}

Note: $n s=$ no significant difference could be found. 
Far Right Reaches towards Glove Box and Passenger Door

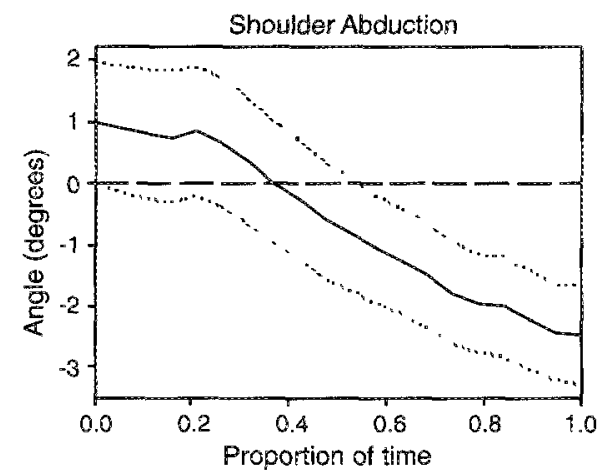

\section{Reaches to Overhead Console}

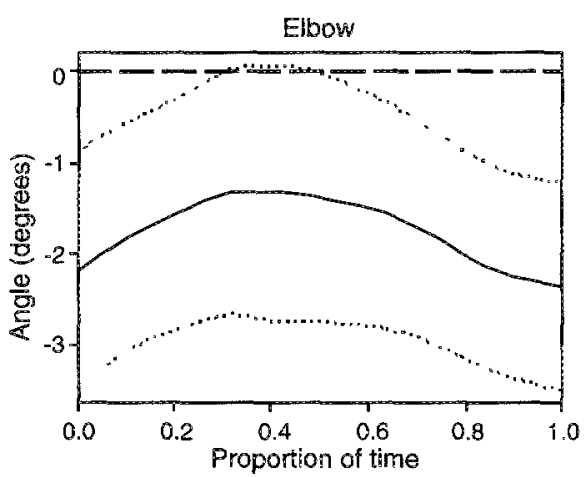

Figure 6. Mean angle differences (and $95 \%$ confidence lines) for the two angles found to have the largest differences attributed to being male compared with female angle predictions.

older group compared with the younger group. It reveals that the largest consistent effect exists in the shoulder horizontal and vertical angles; the older participants tended not to elevate (abduct) their arm as much and did not rotate their shoulder forward as much as did the younger participants. In essence, the older participants tended to keep their elbows closer to their torsos during the various reaches. Inspection of the reach graphs depicted in Figure 7 shows that this "conserv. ative" arm posture is consistent throughout the reach motions, not merely at the teminal postures analyzed in Tabie 5 .

\section{DISCUSSION}

We believe this study illustrates a new method of studying and characterizing how various population attributes can affect human motions and preferred reach postures. Such a method provides a new means to understand complex human motions and, perhaps, to resolve the 75-year-old Bernstein problem: How does the human body coordinate a large number of muscles and joint rotations so that the hand trajectory is "well bchaved"(Latash, 1998)?

We believe this approach also indicates how stature, a dominating factor in movement characterization, can be removed from an analysis to reveal more subtle effects arising from other population attributes (e.g., age and gender). It is interesting to note that when this was done, we found that the older participants preferred to keep the elbow closer to the torso than did younger participants. One reason for this may be related to the work described by Hughes and An (1997), which showed that small

TABLE 5: Summary of Significant Mean Changes in Six Major Body Angles (in degrees) for Subjects Over 50 Years Compared with Those Under 50 Years when the Hand Reached the Four Final Target Areas

\begin{tabular}{lllllll}
\hline $\begin{array}{l}\text { Target } \\
\text { Area }\end{array}$ & $\begin{array}{l}\text { Trunk } \\
\text { Forward }\end{array}$ & $\begin{array}{l}\text { Trunk } \\
\text { Lateral }\end{array}$ & $\begin{array}{l}\text { Trunk } \\
\text { Rotation }\end{array}$ & $\begin{array}{l}\text { Shoulder } \\
\text { Vertical }\end{array}$ & $\begin{array}{l}\text { Shoulder } \\
\text { Horizontal }\end{array}$ & $\begin{array}{l}\text { Right } \\
\text { Elbow }\end{array}$ \\
\hline Console & $n s$ & $n s$ & $1.5^{\circ}$ & $-2.4^{\circ}$ & $-3.4^{\circ}$ & $n s$ \\
Radio & $1.1^{\circ}$ & $n s$ & $1.3^{\circ}$ & $-2.3^{\circ}$ & $-7.1^{\circ}$ & $n s$ \\
Overhead & $1.2^{\circ}$ & $n s$ & $n s$ & $-3.0^{\circ}$ & $-5.6^{\circ}$ & $n s$ \\
Far Right & $1.8^{\circ}$ & $-1.2^{\circ}$ & $1.5^{\circ}$ & $-4.4^{\circ}$ & $-4.6^{\circ}$ & $n s$ \\
\hline
\end{tabular}

Note: $n s=$ no significant difference could be found. 
Reaches to Radio
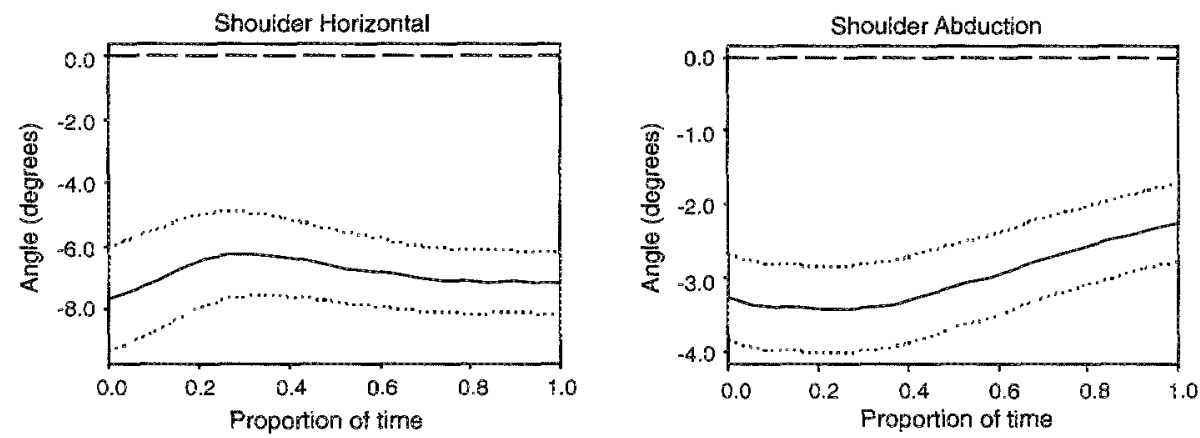

Far Right Reaches towards Glove Box ano' Passenger Door
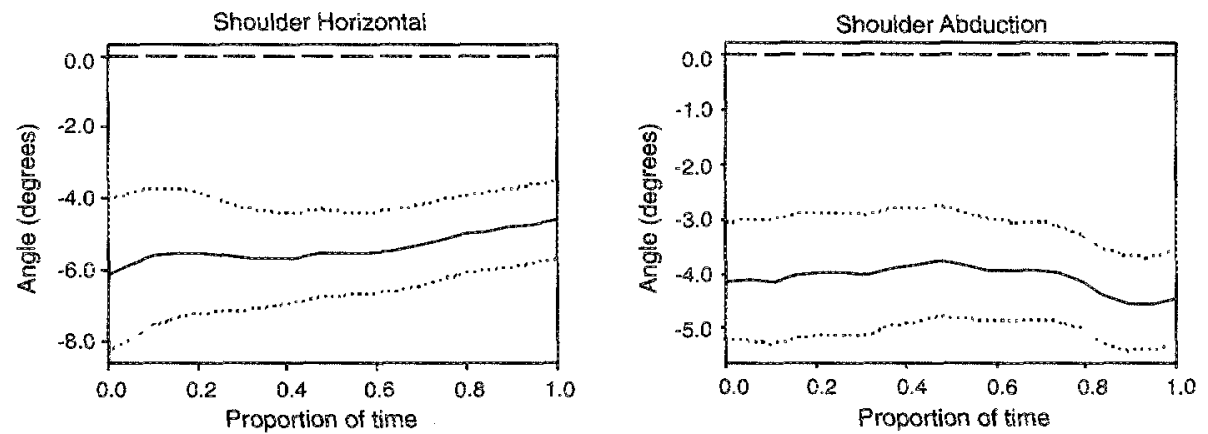

Figure 7. Mean angle differences (and $95 \%$ confidence lines) for the shoulder angles with differences attributable to being older than 50 years compared with being younger than 50 years.

changes in humeral rotation during reaching motions can have large effects on glenohumeral joint contact forces and rotator tendon forces, which often can cause irritable tissues in older shoulder structures. One simulation study by Chaffin et al. (1998), using a shoulder biomechanical model developed by Hogfors, Karlsson, and Peterson (1995), showed that reaches to the glove box area by a large young man resulted in about $10 \%$ less glenohumeral contact force than did those by a small young woman, who had to abduct her arm more.

Despite the positive findings of this study, limitations are evident. For instance, the reaches were performed without any weight in the hand. Strength limitations are known to affect at least static postures (Chaffin, Faraway, \&. Zhang, 1999) so it is reasonable to expect differences in motions as the dynamic moments at the shoulder and other joints increase because of moving objects in the hand. This may be particularly relevant to older individuals with diminished shoulder strength and range of motion when lifting objects in and out of a vehicle. The fact that the small, older women in this study had to abduct their shoulders to an extreme angle when reaching to the passenger door or glove box raises questions of how best to locate and design inside door handles, window controls, and other manually operated devices for such a group. In this study the participants simply had to push small buttons, not grasp handles or apply forces in different directions. The latter requirement would certainly alter the terminal reach postures depicted in this study.

Another limitation in the study is the type of vehicle and seat used. Though it is believed that the vehicle seat used is reasonably indicative of a typical passenger car seat, it certainly does not represent all types of vehicles (e.g., bus, truck, van, and sport utility vehicle seats). 


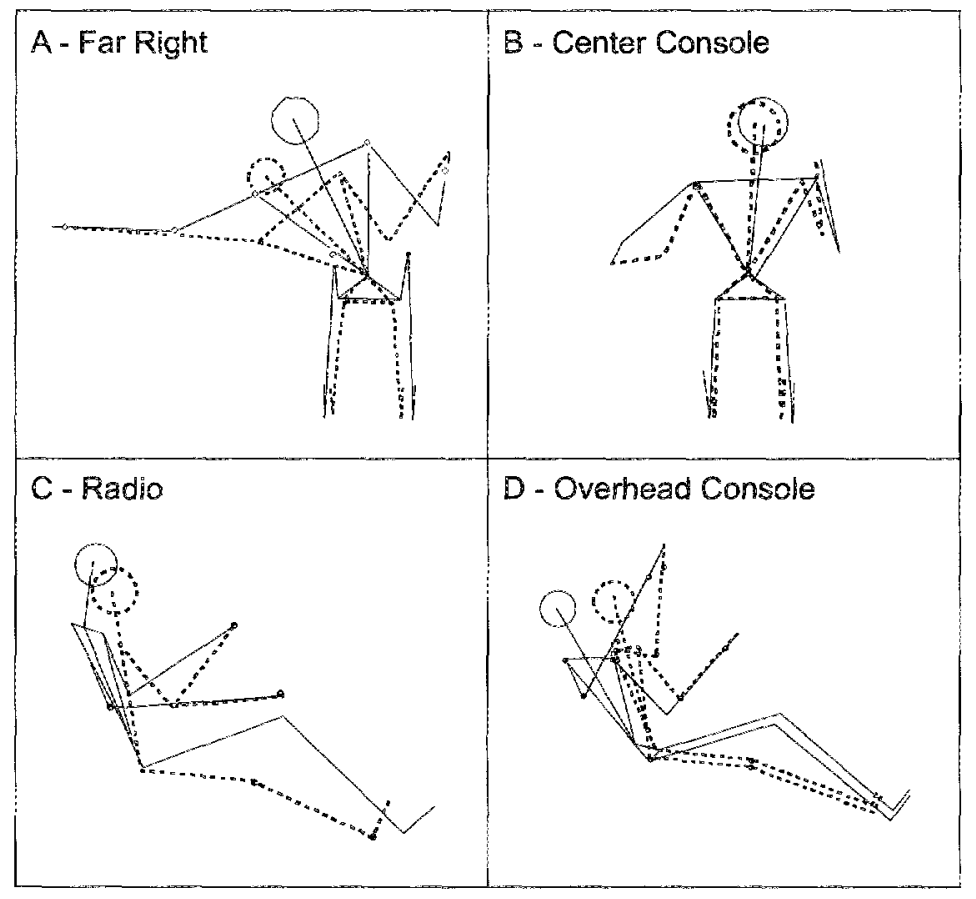

Figure 8. Terminal postures for reaches to the four target areas (A) far right toward glove box/passenger door, (B) center console, (C) radio, and (D) overhead console, depicting combined multivariate cffects of stature, age, and gender. Solid lines indicate large (95th percentile) 21-year-old male predicted postures, and dashed lines indicate small (5th percentile) 65-year-old female predicted postures. The two upper panels are front views and the bottom two are side views.

The use of less-contoured and higher seats probably would result in larger torso motions.

\section{CONCLUSIONS}

With the experimental and statistical modeling methods described in this paper, it is possible to capture and predict even small variations in reach motions. In the reach motions depicted in this study, it is clear that anthropometry (as represented by stature) is a very important demographic variable. Age and, to a much lesser degree, gender also account for some consistent differences. Their combined multivariate effects are graphically depicted in Figure 8 , in which the model predicts the postures of a small (about 5 th percentile stature of U.S. population) 65-year-old woman compared with a large (about 95 th percentile stature of U.S. population) 21-year-old man reaching to the four different target areas.

As depicted in the terminal postures in Figure 8 , the combined effects of stature, age, and gender are profound. When arm abduction shoulder angles approach $135^{\circ}$, as is the case depicted in Figure 8 a for a small older woman reaching to the far right passenger-side door, one must be concerned. Such a posture was found by Chaffin et al. (1998) to be very limiting for many women and some men because of the shoulder strength required in such a reach. This would be further aggravated if the person in such a posture had to exert a significant hand force in a direction nomal to the arm posture (e.g., operating a manual window or door handle). Even the less extreme reach to the center console was found to be associated with different terminal postures and motions, depending on stature, age, and gender, as depicted in the postures associated with reaching to the center (shift) console depicted in Figure $8 \mathrm{~b}$. Here the reach to the center console shows that for a small older woman performing such a reach, the elbow is kept closer to the body than for a large young man. In contrast, when reaching forward to the radio or overhead (Figures $8 \mathrm{c}$ and $8 \mathrm{~d}$, 
respectively) the small older women were found to use a more erect torso posture and more shoulder abduction, mostly related to their smaller size. If size (stature) is equal, then older participants tended to keep the arm closer to the body during these latter two reaches than did the younger group, as noted earlier.

It also should be noted that only a simple four-link human kinematic model was used to derive these conclusions regarding the effects of stature, age, and gender. In particular, adding separate pelvic and clavicle motions to the torso motions should provide a much more robust method of depicting complex motions for both seated and standing reaches. Such a model is now being developed in the University of Michigan Human Motion Simulation Laboratory. With this revised model and with additional reach studies that include the effects of hand loads and handle orientations, we should be able to depict and simulate an even larger array of realistic reach motions for future human simulations and computer-aided design applications described by Badler et al. (1993). We expect that this technology will greatly improve the use of ergonomics principles in future computer-assisted vehicle design systems as defined by Peacock and Karwowski (1993). These human simulation systems will provide much more precise analysis of reach capability, object avoidance, and joint biomechanical injury risk than currently exists.

\section{ACKNOWLEDGMENTS}

The authors acknowledge the partial support provided for this project by a Chrysler Challenge Fund Grant and the helpful advice and editorial assistance of Deborah Thompson. We are also indebted to the University of Michigan Claude D. Pepper Older Americans Independence Center (NIA Grant AGO8808) for assistance in locating appropriate participants.

\section{REFERENCES}

Badler, N. I., Phillips, C. B., \& Webber, B. L. (1993). Simulating himuns. New York: Oxford University P'ress.

Cavanaugh, \}. T., Shinberg. M., Ray, L., Shipp, K. M., Kuchibhatla, M., \& Schenkman, M. (1999). Kinematic characterization of standing reach: Comparison of younger vs. older subjects. Cinical Biomechanics, 14, 271 -279.

Chaffin, D. B., Andersson, G. B. J., \& Martin, B. I. (1999).
Occupational biomechanics (3rd ed.). New York: Wiley.

Chaffin, D. B., Faraway, J., \& Zhang, X. (1999). Simulating reach motions. Presented at the SAE Human Modeling for Design and Engineering Conforence, The Hague, Netherlands. Pittsburgh: Society of Autonotive Engineers.

Chaffin, D. B., Georgi, C., Baker, G., \& Nussbaum, M. (1998). Dynamic shoulder loads in reaching and materials handling tasks. In Proceedings of the Human Factors and Ergonomics Society 42nd Annual Meeting (pp. 917-920). Santa Monica, CA: Human Factors and Ergonomics Society.

Faraway, 1. (1997). Regression analysis for a functional response. Technometrics, $39.254-262$

Gallagher, M. A. Zuckerman, J. D., Cuomo, F. \& Ortiz, J. (1996). The effect of age, speed, and arm dominance on shoulder function in untrained men. Journal of Shoulder and Elbow Surgery, $5(1), 35-41$

Haywood, K. M., Williams, K., \& VanSunt, A. (1991). Qualitative assessment of the backswing in older adult throwing. Research Quarteriy for Exercise and Sport, 62, 340-343.

Hogfors, C., Karlsson, D., \& Peterson, B. (1995). Structure and internai consistency of a shoulder model. Joumal of Biomechanics, 28, 767-777.

Hughes, R. E., \& An, K. N. (1997, September), Monte Carlo simulation of a plana" shoulder model. Medical and Biological Engineering and Computing, pp. 544-548.

Karwowski, W., Genaidy, A. M., \& Asfour, S. S. (F.ds.). (1990). Computer-aided ergonomics (pp. 138-156). London: Taylor \& Francis.

Kumar, S., Chaffin, D. B., \& Redfem, M. (1988). Isomerric and isokinetic back and arm lifting strengths: Device and measurement. Journal of Biomechanics, 21, 35-44.

Latash, M. L. (1998). Progress in motor control: Bernstein's Traditions in Movement Studies, Vol. 1. Champaign, II: Human Kinetics.

Laubach, L. I. (1978). Human muscular strength. In Webt Associates (Eds.), Anthropometric source book: Vol. 1 (NASA Ref. 1024). Houston: NASA Seientific and Technical Information Office.

Lawton, M. P. (1990). Aging and performance of home tasks. Human Factors. 32, 527-536.

Murray, M. P., Gore, D. R., Gardner, (i. M., \& Mollinger, L. A. (1985). Shoulder motion and muscle strength of normal inen and women in two age groups. Clinical Orthopedics, 198 , $268-273$.

National Center for Health Statistics. (NCHS), (1976). Height and weight of aiduls 18.74 years old in the United States (Advanced Data HANES Survey series 10 and 11, No. 3, pp. 1-8). Hyattsville, MD.

Nussbaum, M. A., Zhang, X., Chaflin, D. B., Stump, B. S., \& Raschke, U. (1996). A reduced surface inarker set for upper limb kinematics: Heuristics and optimization. In Proceedings of the 20th Annual Meeting of American Bociery of Biomechanics (pp. 251-252). Ann Arbor, MI: American Society of Bionechanics.

Peacock, B. L., \& Karwowski, W. (1993). Automotive ergonomics. Bristol, PA: Taylor \& Francis.

Potvin, A. R., Syndulko, K., Toutellotte, W. W., Lernmon, I. A., \& Potvin, J. H. (1980). Human netrologic function and the aging process. Joumal of the Anerican Geriatrics Society, 28, 1-9.

Ramsay, J., \& Silverman, B. (1997). Functional data analysis. New York: Springer-Verlag.

Yates, J. W., Kamon, E., Rodgers, S. H., \& Champney, P. C. (1980). Static lifting strength and maximai isometric voluntary contractions of back, arm, and shoulder muscles. Ergonomics. $23,3747$.

Zhang, X., \& Chaffin, D. B. (1997). Task effects on three-dimensional dynamic postures furing seated reaching movements: An investigative scheme and illustration. Human Factors, 39 , $659-671$.

Don B. Chaffin is a professor in the Departments of Industrial and Operations Engineering and Biomedical Engineering at the University of Michigan. He received his Ph.D. in industrial enginecring from the University of Michigan in 1968. 
Julian J. Faraway is a professor in the Department of Statistics at the University of Michigan. He received his Ph.D. in statistics from the University of California, Berkeley in 1987.

Xudong Zhang is an assistant professor in the Department of Mechanical and Industrial Engineering at the University of Mlinois-Champaign. He received his $P h . D$. in industrial and operations engineering from the University of Michigan in 1997.
Charles Woolley is a research engineer in the Center of Ergonomics at the University of Michigan. He received his masters degree in bioengineering from the University of Michigan in 1980.

Date received: July 30, 1999

Date accepted: February 15, 2000 


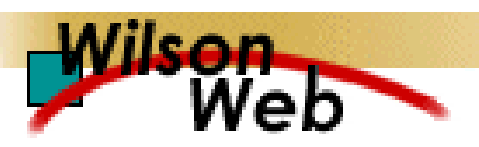

\section{COPYRIGHT INFORMATION}

TITLE: Stature, age, and gender effects on reach motion postures SOURCE: Human Factors 42 no3 Fall 2000

WN: 0028902939006

The magazine publisher is the copyright holder of this article and it is reproduced with permission. Further reproduction of this article in violation of the copyright is prohibited..

Copyright 1982-2002 The H.W. Wilson Company. All rights reserved. 